\title{
Unequal access and unmet need: neurotic disorders and the use of primary care services
}

\author{
P. E. BEBBINGTON,${ }^{1}$ H. MELTZER, T. S. BRUGHA, M. FARRELL, R. JENKINS, \\ C. CERESA AND G. LEWIS
}

From the Department of Psychiatry and Behavioural Sciences, RF \& UCL Medical School, Institute of Psychiatry and Office for National Statistics, London; Department of Psychiatry, University of Leicester; Ninewells Hospital and Medical School, Dundee; and University of Wales College of Medicine, Department of Psychological Medicine, Cardiff

\begin{abstract}
Background. In this paper we use data from the National Survey of Psychiatric Morbidity to examine how many people with neurotic disorders receive professional evaluation, and how this is affected by clinical and sociodemographic differences. We hypothesized that psychiatric symptoms and attendant dysfunctions would both have an effect on contacting, and that key demographic variables would not.

Method. The household component of the British National Surveys of Psychiatric Morbidity was based on a random sample of $>10000$ subjects. Psychiatric symptoms and ICD-10 diagnosis were established by lay interviewers using the CIS-R. Social dysfunction was tapped by asking about difficulties in performing seven types of everyday activity. We examined symptom score, ADL deficit score and demographic variables in relation to contact with primary care physicians for psychiatric symptoms.

Results. The major determinant of contacting a primary care physician was severity, mainly due to the level of psychiatric symptoms, but with an independent contribution from social dysfunction. There were also significant contributions from sex, marital status, age, employment status and whether the subject had a physical condition as well.

Conclusions. The major influence on whether people seek the help of their family doctors for mental health problems is the severity of disorder. Although there are some social inequalities in access to family doctors, these are less important. The most salient finding from our study is that even people suffering from high levels of psychiatric symptoms very often do not have contact with professionals who might help them.
\end{abstract}

\section{INTRODUCTION}

One of the purposes of the British National Surveys of Psychiatric Morbidity (Jenkins et al. 1997a) was to obtain indirect assessments of needs for care. The prevalence of psychiatric disorders can be taken as a rough indication of the overall need for psychiatric treatment in a

\footnotetext{
1 Address for correspondence: Professor Paul E. Bebbington, RF \& UCL London Medical School, Department of Psychiatry and Behavioural Sciences, Archway Campus, Whittington Hospital, Highgate Hill, London N19 5NF.
}

general population. Some kind of service contact is required before most treatments can be given. The household component of the National Surveys collected information about diagnosis, service use and the receipt of pharmacological and psychological treatments. Combining these does at least allow reasonable estimates of the extent to which needs are not being met by services. In this paper we focus on the first stage in obtaining treatment, that is, contact with a primary care physician for a mental health problem. In a companion paper (Bebbington et al. 2000a), we investigate the influences that 
bear on the provision of pharmacological and psychological treatments.

Within the British National Health Service, the twin principles of equity and proportionality are particularly important. We expected that only a minority of people diagnosed as cases of psychiatric disorder would seek professional help for their symptoms and receive treatment for them. In a context of limited uptake, one would at least hope that these principles would exert an appreciable influence. In other words, a greater proportion of severe disorders would receive treatment than mild ones, and disorders of equivalent severity would be equally likely to be treated whatever the attributes of the person suffering from them. The application of both principles would tend to result in severity being the major determinant of treatment, and treatment access would not vary in relation to sociodemographic variables.

The severity of psychiatric disorders has more than one component. In this paper, we use as measures of severity the number of psychiatric symptoms and a measure of concomitant dysfunction. In an earlier paper (Bebbington et al. $2000 \mathrm{~b}$ ), we have shown that these attributes, while correlated, are sufficiently separate to merit using both as independent variables. In the UK, while most people in the general population who are identified as having a psychiatric disorder will not have sought professional help, those who do will mainly be seen by primary care physicians.

In this current paper, we therefore examine the association of symptom severity, dysfunction as indicated by difficulties in activities of daily living, and sociodemographic variables with seeking help from primary care physicians for a psychiatric problem. We hypothesized that the major determinant of contacting a general practitioner for a psychiatric problem would be the severity of the problem, and thus the proportion of people contacting would be little affected by demographic variables once severity was accounted for.

\section{METHOD \\ Sampling}

The methods used in the household survey of psychiatric morbidity have been described in greater detail elsewhere (Jenkins et al. $1997 a, b$;
Meltzer et al. 1995a,b,c). The fieldwork was carried out in 1993. The sample was drawn using the small area Postcode Address File as the sampling frame. Two hundred postal sectors covering all of Great Britain, except the Highlands and Islands of Scotland, were selected at random with a probability proportional to the number of delivery points. Within these, 90 delivery points were randomly selected to generate a sample of 18000 delivery points. From among these addresses, private households with at least one person aged 16 to 64 were identified. In all, 15765 private households were identified and provided 12730 adults eligible for interview, of whom 10108 agreed to take part in the survey. Only one eligible adult (i.e. aged 16-64) was interviewed in each household systematically selected by the Kish grid method (Kish, 1965). Probability weights were used to take account of this sampling procedure and also to render the sample representative of the demographic characteristics of the population in Britain.

\section{Interviewers and interviewer training}

The interviews were carried out by 200 interviewers from the Social Survey Division field force of the British Office for Population Censuses and Surveys (now the Office for National Statistics, ONS). These interviewers had a minimum of 3 years' prior interviewing experience and attended for a 1 day training programme in the use of the survey instruments, including the revised Clinical Interview Schedule (CIS-R; Lewis et al. 1992). Fieldwork was closely monitored by supervisors in the field and by headquarters staff.

\section{Assessment}

Neurotic psychiatric disorder was assessed using the CIS-R. This has advantages that made it suitable for the National Survey. It can be administered by non-clinically trained interviewers, and training in the use of the schedule was straightforward for the experienced ONS interviewers used in the survey. Moreover, the interview itself is relatively short (on average, $30 \mathrm{~min}$ ) compared with other methods of assessment.

The CIS-R is made up of 14 sections. Each section covers a particular area of neurotic symptoms, and starts with a variable number of 
mandatory questions that can be regarded as sift or filter questions. They establish the existence of a particular neurotic symptom in the past month. A positive response to these questions leads the interviewer on to further enquiry giving a more detailed assessment of the symptom in the past week: frequency, duration, severity and time since onset. It is the answers to these questions that determine the informant's score on each section. More frequent and more severe symptoms result in higher scores.

The minimum score for each section is 0 , where it was either not present in the past week or was present only in mild degree. The maximum score is 4 (except for the section on Depressive Ideas, which has a maximum score of 5). Thus, summed scores from all 14 symptom sections could in theory range between 0 and 57 . The overall threshold score for significant psychiatric morbidity is 12 . In this paper, we have based analyses on a fourfold categorization $(0-5 ; 6-11 ; 12-17 ; \geqslant 18)$ rather than on total score. These categories were chosen to straddle the case threshold and to contain analysable numbers of subjects. In the interests of simplicity of interpretation, this allowed us to calculate weighted relative odds of contacting the family doctor for mental health reasons.

The CIS-R also provides prevalences relating to a 1 -week period. Basic symptom data are subjected to a computer algorithm providing ICD-10 diagnoses. All those scoring above 12 on the CIS-R who were not allocated to specific ICD-10 categories were classed as suffering from mixed anxiety and depressive disorder (F41.2). We applied a hierarchy to the diagnostic categories, so that each subject could be allocated to a single primary diagnosis (see Table 1).

Our measure of concomitant dysfunction was based on difficulties with activities of daily living. It has been described in detail by Bebbington and his colleagues $(2000 \mathrm{~b})$. Subjects could score zero, one or two on seven areas of difficulty (personal care, using transport, medical care, household activities, practical activities, dealing with paperwork, managing money) and scores were summed to produce an overall measure of social dysfunction. This ADL deficit score was collapsed into four categories for some analyses $(0 ; 1-2 ; 3-4 ; \geqslant 5)$.

Some information about consultations with general practitioners was asked of all respon- dents, with more detail being requested of subjects with neurotic disorders. All informants were asked if they had spoken to their GP in the past year, and whether it was for physical or for mental and emotional complaints.

We also enquired from people with neurotic disorder about their contact with secondary care services. Information was collected about visits to a hospital or clinic, or anywhere else providing treatment or check-ups. These included hospitals, day-hospitals, clinics and private consulting rooms. It also included attendance at daycentres for treatment, but not attendance for leisure purposes. This subgroup was also asked about in-patient stays within the last year, that is, a stay in hospital for one night or longer for treatment or for tests. They were also asked whether they had received a visit in their home from people delivering a range of services: these include community psychiatric nurses, occupational therapists, social workers, psychiatrists, home care workers or home helps and voluntary workers.

Information about social class, marital status, ethnic origin, employment status and age was obtained from the subjects. In the analyses of social class we excluded those in the armed forces and those who could not be allocated to a group because there was insufficient information or they had never worked. Marital status categories were collapsed into single; married and cohabiting; and the divorced, widowed and separated. Information about ethnic origin was classified in accord with the official census groupings, but these were then collapsed into a four-fold classification: White; Black (African, African-Caribbean, and 'Black Other'); South Asian (Indian, Pakistani, Bangladeshi); and 'Other'. Employment status also covered four groups: working full-time; working part-time; unemployed; and, economically inactive.

Analyses were based on all respondents who were directly interviewed in the National Survey with the exception of the 54 cases who were identified as having a psychotic disorder. Two hundred and seventy-one subjects assessed by proxy were not included, as there were no CIS-R data on them. Analyses were based on weighted data. Logistic regression was performed using STATA 6.0 (StataCorp, 1999), which allows the use of data modified by probability weights. 
Table 1. Hierarchy of functional disorders used to establish single primary diagnosis

\begin{tabular}{lll}
\hline \hline Disorder 1 & Disorder 2 & \multicolumn{1}{c}{ Priority } \\
\hline Psychosis & Any & Psychosis \\
Depressive episode (any severity) & Phobia & Depressive episode (any severity) \\
Depressive episode (mild) & OCD & OCD \\
Depressive episode (moderate) & OCD & Depressive episode (moderate) \\
Depressive episode (severe) & OCD & Depressive episode (severe) \\
Depressive episode (mild) & Panic disorder & Panic disorder \\
Depressive episode (moderate) & Panic disorder & Depressive episode (moderate) \\
Depressive episode (any severity) & GAD & Depressive episode (any severity) \\
Phobia (any) & OCD & OCD \\
Agoraphobia & GAD & Agoraphobia \\
Social phobia & GAD & Social phobia \\
Specific phobia & GAD & GAD \\
Panic disorder & OCD & Panic disorder \\
OCD & GAD & OCD \\
Panic disorder & GAD & Panic disorder \\
\hline \hline
\end{tabular}

GAD, Generalized anxiety disorder; OCD, Obsessive-compulsive disorder.

\section{RESULTS}

Full details of the effectiveness of the sampling strategy are given by Jenkins et al. (1997b).

In Table 2 we examine the influence of the presence of neurotic disorder on primary care consultations for mental problems in the year prior to interview. The results are presented separately for males and females. Seventy-four per cent of men and $60 \%$ of women with neurotic disorders had not in fact consulted their GP for a mental complaint. Relatively high levels of contacting were seen for depressive disorder, and in females the highest rate of contacting was in obsessive-compulsive disorder. A small percentage of people who were not currently suffering from a psychiatric disorder had been in contact, and so it is possible that at the time they might have met the criteria for one or more of the neurotic disorders identified by the CIS-R.

In order to examine the effect of severity on

Table 2. Contact with GP for mental problems (past year) and the type of neurotic disorder (weighted data)

\begin{tabular}{lccccccccc}
\hline \hline & \multicolumn{1}{c}{ Type of disorder } \\
\cline { 2 - 10 } & $\begin{array}{c}\text { Mixed anxiety } \\
\text { and depressive } \\
\text { Adults in } \\
\text { contact }\end{array}$ & $\begin{array}{c}\text { Generalized } \\
\text { anxiety } \\
\text { disorder }\end{array}$ & $\begin{array}{c}\text { Depressive } \\
\text { episode }\end{array}$ & Phobia & $\begin{array}{c}\text { Obsessive- } \\
\text { compulsive } \\
\text { disorder }\end{array}$ & Panic & $\begin{array}{c}\text { No } \\
\text { disorder }\end{array}$ & $\begin{array}{c}\text { Any } \\
\text { neurotic } \\
\text { disorder }\end{array}$ & Total \\
\hline Males, $\%$ & $23 \cdot 5$ & $25 \cdot 2$ & $40 \cdot 2$ & $35 \cdot 3$ & $21 \cdot 7$ & $24 \cdot 3$ & $4 \cdot 7$ & $26 \cdot 3$ & $7 \cdot 7$ \\
Base, $N$ & 264 & 135 & 83 & 34 & 46 & 37 & 4233 & 609 & 4832 \\
Females, $\%$ & $32 \cdot 8$ & $41 \cdot 9$ & $50 \cdot 8$ & $42 \cdot 3$ & $56 \cdot 9$ & $39 \cdot 5$ & $9 \cdot 8$ & $39 \cdot 8$ & $17 \cdot 2$ \\
Base, $N$ & 488 & 167 & 123 & 71 & 72 & 43 & 3947 & 964 & 4911 \\
\hline \hline
\end{tabular}

Table 3. GP consultations for mental disorder (past year) by symptom score and sex (weighted data)

\begin{tabular}{|c|c|c|c|c|}
\hline \multirow{2}{*}{$\begin{array}{l}\text { Attended } \\
\text { for mental } \\
\text { disorder }\end{array}$} & \multicolumn{4}{|c|}{ Symptom score } \\
\hline & $0-5$ & $6-11$ & $12-17$ & $\geqslant 18$ \\
\hline Male, \% & $3 \cdot 5$ & $11 \cdot 4$ & $19 \cdot 2$ & $38 \cdot 1$ \\
\hline Base, $N$ & 3536 & $\begin{array}{c}773 \\
x^{2}=36\end{array}$ & $\begin{array}{l}266 \\
P<0.0\end{array}$ & 257 \\
\hline $\begin{array}{c}\text { Female, \% } \\
\text { Base } N\end{array}$ & $\begin{array}{c}7 \cdot 1 \\
2917\end{array}$ & $\begin{array}{l}18 \cdot 3 \\
1116 \\
\gamma^{2}=64\end{array}$ & $\begin{array}{c}32 \cdot 6 \\
439 \\
P<0 \cdot 0\end{array}$ & $\begin{array}{c}48 \cdot 9 \\
438\end{array}$ \\
\hline
\end{tabular}


Table 4. GP consultations for mental disorder (past year) by ADL deficit score (weighted data)

\begin{tabular}{|c|c|c|c|c|}
\hline \multirow{2}{*}{$\begin{array}{l}\text { Attended for } \\
\text { mental disorder }\end{array}$} & \multicolumn{4}{|c|}{ ADL deficit score } \\
\hline & 0 & $1-4$ & $5-9$ & $\geqslant 18$ \\
\hline \multirow{3}{*}{$\begin{array}{l}\text { Male, \% } \\
\quad \text { Base, } N\end{array}$} & \multirow{3}{*}{$\begin{array}{l}5 \cdot 8 \\
4077\end{array}$} & \multirow{3}{*}{$\begin{array}{l}12 \cdot 4 \\
193 \\
\chi^{2}=1\end{array}$} & \multirow{2}{*}{$\begin{array}{l}15 \cdot 0 \\
247\end{array}$} & \multirow{2}{*}{$\begin{array}{c}33 \cdot 3 \\
138\end{array}$} \\
\hline & & & & \\
\hline & & & $; P<0$ & \\
\hline \multirow{3}{*}{$\begin{array}{c}\text { Female, } \% \\
\text { Base, } N\end{array}$} & \multirow{3}{*}{$\begin{array}{l}13 \cdot 4 \\
4108\end{array}$} & $24 \cdot 5$ & $24 \cdot 0$ & \multirow{3}{*}{$\begin{array}{l}44 \cdot 1 \\
152\end{array}$} \\
\hline & & 220 & 217 & \\
\hline & & \multicolumn{2}{|c|}{$\chi^{2}=120 \cdot 4 ; \mathrm{df}=3 ; P<0.00001$} & \\
\hline
\end{tabular}

contact we divided subjects according to their symptom score on the CIS-R (Table 3). The relationship between this score and whether the subjects attended their general practitioner for reasons of mental health in the previous year was significant beyond the $0.001 \%$ level. This relationship stands despite the possibility that people attending earlier in the year might have lost some or all of their psychiatric symptoms by the time of interview. Less than $4 \%$ of men in the lowest symptom range had contacted their GP in this way, in comparison with nearly $40 \%$ in the higher symptom score bracket. Nevertheless, even in these high scoring men, $>60 \%$ had not contacted their GP in the previous year. Among females, contact rates were generally somewhat higher. Seven per cent of the low scorers had contacted their GP, in comparison with nearly half of the high scorers.

In Table 4, we perform an equivalent analysis in relation to the Activities of Daily Living (ADL) deficit score. Again, there is a strong relationship, although not so marked as with the symptom score. Both these analyses confirm that the severity of disorder has a major influence on whether people in the general population seek help from their primary care physician for mental problems. However, the possibility remains that there are inequalities in access to treatment in different demographically defined groups.

Our next analysis was a logistic regression examining the effect of severity of illness on contacting behaviour, but including key sociodemographic variables. The variables we included were age, sex, marital status, employment status, ethnicity, social class and whether the subject also reported suffering from a physical illness. The model of best fit, based on this logistic regression, is shown in Table 5. It is clear that the major contribution comes from psychiatric symptoms, and subjects scoring $\geqslant 18$ on the CIS-R were nearly eight times as likely to have been in contact with their primary care physician for mental health reasons than people scoring $\leqslant 5$. However, as might be inferred from Table 4, difficulties in daily living activities also provides a significant independent contribution, even after controlling for age, with which, as might be expected, it has a strong relationship (Bebbington et al. 2000 b).

Thus, our argument that the severity of disorder is the major determinant of contacting behaviour is supported. Nevertheless, there were also significant demographic variations. Women were $70 \%$ more likely than men to contact their family doctor with a mental health problem, even after severity of illness was controlled. The presence of a physical illness also had an impact in increasing the likelihood of contact. People who suffered from a physical illness were twice as likely to contact their GP with a mental health problem. The other variables that contributed significantly to our final model were age, marital status and employment status. There was a significant, but small, contribution from ethnic group.

It is notable that social class was not required in the model of best fit. If a simple model incorporating terms representing symptom severity, social impairment and social class is tested, the last-named term does contribute significantly and appreciably to the model of best fit: people with unskilled occupations were around twice as likely to make contact as those in professional posts. However, the effect of social class is eliminated by incorporating the single additional term representing sex. In other words, the tendency of women to be allocated to lower social economic groups accounts for the 
Table 5. GP consultation for a mental problem severity of disorder and sociodemographic variables. Model of best fit (weighted data)

\begin{tabular}{|c|c|c|c|c|}
\hline Factors & Adjusted ORs & $95 \% \mathrm{CI}$ & $z$ & $P$ \\
\hline \multicolumn{5}{|l|}{ Symptom score } \\
\hline $0-5$ & $1 \cdot 00$ & - & & \\
\hline $6-11$ & $2 \cdot 93$ & $2 \cdot 4-3 \cdot 5$ & $11 \cdot 51$ & $0 \cdot 0001$ \\
\hline $12-17$ & $4 \cdot 26$ & $3 \cdot 3-5 \cdot 5$ & $10 \cdot 76$ & $0 \cdot 0001$ \\
\hline$\geqslant 18$ & 7.78 & $6 \cdot 0-10 \cdot 2$ & 15.05 & 0.0001 \\
\hline \multicolumn{5}{|l|}{ ADL deficit score } \\
\hline 0 & $1 \cdot 0$ & - & & \\
\hline $1-2$ & $1 \cdot 34$ & $1 \cdot 0-1 \cdot 8$ & $1 \cdot 91$ & 0.056 \\
\hline $3-4$ & $1 \cdot 19$ & $0 \cdot 9-1 \cdot 6$ & $1 \cdot 23$ & $0 \cdot 22$ \\
\hline$\geqslant 5$ & $2 \cdot 02$ & $1 \cdot 5-2 \cdot 7$ & $4 \cdot 52$ & $0 \cdot 0001$ \\
\hline \multicolumn{5}{|l|}{ Physical illness } \\
\hline Absent & $1 \cdot 00$ & - & & \\
\hline Present & 1.96 & $1 \cdot 5-2 \cdot 5$ & $5 \cdot 37$ & $0 \cdot 0001$ \\
\hline \multicolumn{5}{|l|}{ Sex } \\
\hline Male & $1 \cdot 00$ & - & & \\
\hline Female & 1.73 & $1 \cdot 5-2 \cdot 0$ & $6 \cdot 27$ & 0.0001 \\
\hline \multicolumn{5}{|l|}{ Marital status } \\
\hline Single & $1 \cdot 00$ & - & & \\
\hline Married etc & $1 \cdot 00$ & $0 \cdot 8-1 \cdot 3$ & $-0 \cdot 005$ & $0 \cdot 97$ \\
\hline Divorced, widowed, separated & $1 \cdot 60$ & $1 \cdot 3-1 \cdot 9$ & $5 \cdot 04$ & 0.0001 \\
\hline \multicolumn{5}{|l|}{ Age, years } \\
\hline $16-24$ & $1 \cdot 00$ & - & & \\
\hline $25-34$ & $1 \cdot 27$ & $1 \cdot 0-1 \cdot 6$ & $1 \cdot 63$ & $0 \cdot 10$ \\
\hline $35-44$ & $1 \cdot 33$ & $1 \cdot 0-1 \cdot 8$ & $1 \cdot 85$ & $0 \cdot 064$ \\
\hline $45-54$ & 1.53 & $1 \cdot 3-2 \cdot 1$ & $2 \cdot 71$ & $0 \cdot 007$ \\
\hline $55-64$ & $1 \cdot 14$ & $0 \cdot 8-1 \cdot 6$ & $0 \cdot 81$ & $0 \cdot 42$ \\
\hline \multicolumn{5}{|l|}{ Employment status } \\
\hline Working full-time & $1 \cdot 00$ & - & & \\
\hline Working part-time & $1 \cdot 30$ & $1 \cdot 1-1 \cdot 6$ & $2 \cdot 42$ & 0.016 \\
\hline Unemployed & $1 \cdot 52$ & $1 \cdot 2-2 \cdot 0$ & $3 \cdot 00$ & 0.003 \\
\hline Economically inactive & 1.54 & $1 \cdot 3-1 \cdot 9$ & $4 \cdot 35$ & 0.001 \\
\hline \multicolumn{5}{|l|}{ Ethnicity } \\
\hline White & $1 \cdot 00$ & - & & \\
\hline Black & $0 \cdot 95$ & $0 \cdot 5-1 \cdot 6$ & $-0 \cdot 18$ & $0 \cdot 86$ \\
\hline South Asian & $0 \cdot 37$ & $0 \cdot 2-0 \cdot 8$ & $-2 \cdot 50$ & $0 \cdot 013$ \\
\hline Other & 0.85 & $0 \cdot 4-1 \cdot 7$ & $-0 \cdot 46$ & $0 \cdot 65$ \\
\hline
\end{tabular}

relationship between socio-economic status and contact with a GP for mental health problems.

The peak of contacting occurred in people aged 45-54, and the likelihood of contact increased gradually from the youngest age group up to this point. Single people were as likely to contact their GP for mental problems as their married counterparts, but contacting was appreciably increased in the divorced, widowed and separated. As noted by some other authors, the South Asian group were particularly unlikely to consult their family doctor for a psychiatric problem, and this applied even after allowance for their comparatively reduced level of symptoms. Finally, those in full-time employment were noticeably different from all other employment groups in their reluctance to consult their GPs for a mental problem, understandable in terms of the practical difficulty of fitting in such a visit.

\section{Other contacts with professional services}

Of people with neurotic disorder, half had undergone check-ups or treatment as outpatients, but the vast majority were for physical complaints. Only 1 in 20 of the group with neurotic disorder had visited psychiatric outpatient or community facilities in the past year. Many of these were no longer attending, and in $60 \%$ of cases this was because they had dropped out, rather than been discharged. Eight per cent of people with neurotic disorder had been visited by clinicians at home in the previous year, about half of these visits being made by social workers. 
Fifteen per cent of women and $12 \%$ of men with neurotic disorder had been in-patients in the preceding year. This is somewhat higher than the percentages for the whole population found in the 1993 General Household Survey (Foster et al. 1995) - 12\% of women and $7 \%$ of men. However, only $1 \%$ of our sample with neurotic disorder had been in-patients in psychiatric facilities in the previous year.

\section{DISCUSSION}

In this paper, we have combined information about diagnosis, severity of disorder and contact with services to draw conclusions about needs for treatment and the extent to which they are unmet. There are potential pitfalls in this process, since diagnosis is only an approximate indication that treatment is needed, and says little about what sort of treatment should be given. Moreover, we are focusing only on the first step in obtaining treatment, that is, making contact with a clinician who might provide it. We found that only a small proportion of people diagnosed as having a neurotic disorder in Britain actually consult their family doctor for treatment. Even if an appreciable number of these people were not in need of treatment, our findings are so dramatic that one must conclude that they represent a large reservoir of untreated psychiatric disorders.

This finding is at some variance with the conclusion reached by Goldberg \& Huxley (1980) in their review of pathways to psychiatric care. They argued that this 'first filter' of making contact with the primary care physician was very permeable, with most people with diagnosable disorders in the community seeking help in this way. They placed weight on findings of Hagnell (1966), Brown \& Harris (1978), Weissman \& Myers (1978) and Wing et al. (1978). However, these studies tended to focus on depression of at least moderate severity, which was more likely to have resulted in a consultation. In some the consultation was not necessarily for a mental problem. Hagnell (1966) also recorded contacting behaviour at any time over a very long period, making an association with neurotic disorder more likely.

More recent studies have presented less optimistic results. Thus, Shapiro and his colleagues (1984) reported on utilization data from three centres of the epidemiologic catchment area (ECA) surveys. In the six months before interview, between 6 and $7 \%$ of adults in the three centres had made visits to health care providers for reasons of mental health. This compares with our finding that $12 \%$ of the sample made mental health related visits in the previous year. In the ECA study, 15 to $20 \%$ of those with a recent DSM-III disorder had made mental health visits, with around $10 \%$ visiting specialists. In our study, of people with a current disorder, around a third had made such visits, although only $5 \%$ saw clinicians working in secondary psychiatric services. This comparison suggests that the central position of primary care in Britain does allow easier initial medical contact for neurotic disorders.

In a nationwide Greek community sample of nearly four thousand people, $60 \%$ of the 570 people reporting serious mental health problems had not sought professional help (Madianos et al. 1993). In a US community sample, of people with three or more symptoms of depression, only a third sought treatment. There were no demographic differences between those who sought help and those who did not (Henderson et al. 1992).

In another United States study, Pollard and colleagues (1989) reported that, of people in the general population suffering from DSM-III agoraphobia, obsessive-compulsive disorder or social phobia, only $40 \%, 28 \%$ and $8 \%$ respectively sought the help of a clinician.

A recent British survey conducted by telephone, found that only $12.5 \%$ of people with depressive disorder had sought help from their general practitioner (Ohayon et al. 1999). However, the authors found a particularly high prevalence of depressive disorder, which suggests they over-recognized cases of depression. The additional 'cases' would have been particularly mild and therefore less likely to contact their GP.

Despite the variations in service structure and provision in different countries, these studies consistently indicate that most people with neurotic disorders do not make contact with professional clinicians who might offer treatment. The available treatments would be effective for many of the people with neurotic disorders identified in our study. Even on a conservative estimation of actual needs, this 
represents a considerable amount of unnecessary suffering and disability.

The first of our concerns in making these analyses has therefore been confirmed. What of the second, that the data on contacting might reveal inequalities of access? Access certainly appears to vary within the different groupings studied, but this is not always easy to attribute to inequality. If there was significant inequality, one might expect it to be reflected in a social class gradient, but we found no such gradient. The greater access of post-marital groups to primary care physicians for mental health problems might actually indicate need increased by social isolation, and may therefore be appropriate. Likewise, people with dual physical and mental problems may need more help, and their increased contact with primary care again may be appropriate. Young people and those in work do seem relatively to neglect themselves or to be neglected, as do men in general, and this requires consideration by those responsible for delivering services and treatment. There is also an appreciable concern that people of South Asian origin may be suffering unnecessarily. There is confusion about whether people from the Indian subcontinent living in Britain are more or less likely to contact their GPs for psychiatric problems than expected (Gillam et al. 1989; Lloyd, 1992; Jacobs et al. 1998). We have shown that on a national scale they contact less and that this is independent of symptom level.

The set of affairs described in this paper inevitably raises two difficult questions: how could we rectify it, and if we could, how might we pay for it? In fact the costs of increased recognition and treatment might not be too great, as the primary care services for mental ill health represent a small proportion of the overall costs of mental health care in the UK (NHS Executive, 1996). Thus, an increase in provision might not greatly extend primary care budgets. Moreover, there are potential savings to be made. Those with psychiatric symptoms make a lot of demands on primary care physicians for reasons ostensibly other than their mental problems. In the household survey described here people identified as having a neurotic disorder were $40 \%$ more likely to have contacted their GP for a physical complaint than respondents with no such disorder (Meltzer et al. 1995b). Thus, more effective targeting of GPs' time might reduce the frequency of ineffective contacts. We propose to use the National Survey data to model these costs and the cost improvements that might be set against them.

The inappropriately low levels of primary care consultation identified in this paper almost certainly indicate an education gap, and this is likely to be shared by primary care physicians and the general public. The best way to augment the education of GPs about mental health has been the subject of study for years (e.g. Goldberg et al. 1980; Andrews \& Hunt, 1999; Gask, 1999), and yet deficiencies certainly remain (Thompson et al. 2000).

There is also no doubt about the adverse impact of public ignorance on take up of psychiatric services (Jorm et al. 1997, 2000). Wells and her colleagues (1994) studied the attitudes towards treatment of people in a general population sample who had psychiatric disorders. Among those who reported reluctance to seek treatment, the two most frequently mentioned reasons were: '... did not think anyone could help' and '... a problem one should be able to cope with'. Our own study of treatment reluctance produced similar results (Meltzer et al. 2000). Angermeyer \& Matschinger (1996) presented psychiatric case vignettes to members of a general population sample as a way of evaluating their attitudes towards psychiatric treatment. They found a clear preference for psychotherapy and a dislike of pharmacotherapy. This dislike appeared to arise from their perception of the specific drawbacks of tranquillizers.

Considerable effort has accordingly been invested in the mental health education of the public, for example, the Royal College of Psychiatrists' 'Defeat Depression' campaign, but these efforts clearly need to be unrelenting. Without these educational improvements, the question of meeting the costs of increased levels of care may be irrelevant.

\section{REFERENCES}

Andrews, G. \& Hunt, C. (1999). The education of general practitioners in the management of mental disorders. In Common Mental Disorders in Primary Care (ed. M. Tansella and G. Thornicroft), pp. 183-193, Routledge: London.

Bebbington, P. E., Brugha, T., Meltzer, H., Jenkins, R., Ceresa, C., Farrell, M. \& Lewis, G. (2000a). Neurotic disorders and the 
receipt of psychiatric treatment. Psychological Medicine 30, 1369-1376.

Bebbington, P. E., Brugha, T., Meltzer, H., Farrell, M., Ceresa, C., Jenkins, R. \& Lewis, G. $(2000 b)$. Psychiatric disorder and dysfunction in the UK National Survey of Psychiatric Morbidity. Social Psychiatry and Psychiatric Epidemiology 35, 191-197.

Brown, G. W. \& Harris, T. (1978). Social Origins of Depression. Tavistock: London.

Foster, K., Jackson, B., Thomas, M., Hunter, P. \& Bennett, N. (1995). General Household Survey, 1993. HMSO: London.

Gask, L. (1999). A course in mental health skills for general practitioners in Manchester. In Common Mental Disorders in Primary Care (ed. M. Tansella and G. Thornicroft), pp. 171-182, Routledge: London

Gillam, S. J., Jarman, B., White, P. \& Law, R. (1989). Ethnic differences in consultation rates in urban general practice. British Medical Journal 299, 953-957.

Goldberg, D. \& Huxley, P. (1980). Mental Illness in the Community: the Pathway to Psychiatric Care. Tavistock: London.

Goldberg, D., Smith, C., Steele, J. J. \& Spivey, L. (1980). Training family doctors to recognise psychiatric illness with increased accuracy. Lancet ii, 521-523.

Hagnell, O. (1966). A Prospective Survey of the Incidence of Mental Disorder. Svenska Bokforlaget Bonniers: Stockholm.

Henderson, J. G. Jr., Pollard, C. A., Jacobi, K. A. \& Merkel, W. T. (1992). Help-seeking patterns of community residents with depressive symptoms. Journal of Affective Disorders 26, 157-162.

Jacobs, K. S., Bhugra, D., Lloyd, K. R. \& Mann, A. H. (1998). Common mental disorders, explanatory models and consultation behaviour among Indian women living in the UK. Journal of the Royal Society of Medicine 91, 66-71.

Jenkins, R., Bebbington, P. E., Brugha, T., Farrell, M., Gill, B., Lewis, G., Meltzer, H. \& Petticrew, M. (1997a). The National Psychiatric Morbidity Surveys of Great Britain-strategy and methods. Psychological Medicine 27, 765-774.

Jenkins, R., Lewis, G., Bebbington, P. E., Brugha, T., Farrell, M., Gill, B. \& Meltzer, H. (1997b). The National Psychiatric Morbidity Surveys of Great Britain - initial findings from the Household Survey. Psychological Medicine 27, 775-790.

Jorm, A. F., Karten, A. E., Jacomb, P. A., Christensen, H., Rodgers, B. \& Pollitt, P. (1997). 'Mental health literacy' a survey of the public's ability to recognise mental disorders and their beliefs about the effectiveness of treatment. Medical Journal of Australia 166, $182-186$

Jorm, A. F., Angermeyer, M. \& Katschnig, H. (2000). Public knowledge and attitudes about mental disorders: a limiting factor in the optimal use of treatment services. In The Unmet Need for Treatment (ed. G. Andrews and A. S. Henderson), pp. 399-413. Cambridge University Press: Cambridge.

Kish, L. (1965). Survey Sampling. John Wiley \& Co: London.

Lewis, G., Pelosi, A. J., Araya, R. C. \& Dunn, G. (1992). Measuring psychiatric disorder in the community: a standardized assessment for use by lay-interviewers. Psychological Medicine 22, 465-486.
Lloyd, K. (1992). Ethnicity, primary care and non-psychotic disorders. International Review of Psychiatry 4, 257-265.

Madianos, M. G., Madianou, D. \& Stefanis, C. N. (1993). Helpseeking behaviour for psychiatric disorder from physicians or psychiatrists in Greece. Social Psychiatry and Psychiatric Epidemiology 28, 285-291.

Meltzer, H., Gill, B., Petticrew, M. \& Hinds, K. (1995a). The Prevalence of Psychiatric Morbidity among Adults Living in Private Households. OPCS Survey of Psychiatric Morbidity in Great Britain. Report 1. HMSO: London.

Meltzer, H., Gill, B., Petticrew, M. \& Hinds, K. (1995b). Physical Complaints, Service Use and Treatment of Adults with Psychiatric Disorders. OPCS Surveys of Psychiatric Morbidity in Great Britain. Report 2. OPCS: London.

Meltzer, H., Gill, B., Petticrew, M. \& Hinds, K. (1995c). Physical Illness, Service Use and Treatment of Adults with Psychiatric Disorders. OPCS Surveys of Psychiatric Morbidity in Great Britain. Report No. 3. OPCS: London.

Meltzer, H., Bebbington, P., Brugha, T., Farrell, M., Jenkins, R. \& Lewis, G. (2000). The reluctance to seek treatment for neurotic disorders. Journal of Mental Health 9, 335-343.

NHS Executive (1996). Burdens of Disease. NHSE: Leeds.

Ohayon, M., Priest, R., Guilleminault, C. \& Caulet, M. (1999). The prevalence of depressive disorders in the United Kingdom. Biological Psychiatry 45, 300-307.

Pollard, C., Henderson Jr., J., Frank, M. \& Margolis, R. (1989). Help-seeking patterns of anxiety-disordered individuals in the general population. Journal of Anxiety Disorders 3, 131-138.

Shapiro, S., Skinner, E. A., Kessler, L. G., Von Korff, M., German, P. S., Tischler, G. L., Leaf, P., Benham, L., Cottler, L. \& Regier, D. A. (1984). Utilization of health and mental health services: three epidemiologic catchment area sites. Archives of General Psychiatry 41, 971-978.

StataCorp (1999). Stata Statistical Software, Release 6.0. Stata Corporation: College Station, TX.

Thompson, C., Kinmonth, A. L., Stevens, L., Peveler, R. C., Stevens, A., Ostler, K. J., Pickering, R. M., Baker, N. G., Henson, A., Preece, J., Cooper, D. \& Campbell, M. J. (2000). Effects of a clinical practice guideline and practice-based education on detection and outcome of depression in primary care: Hampshire depression project randomised controlled trial. Lancet 355, 185-191.

Weissman, M. M. \& Myers, J. K. (1978). Rates and risks of depressive disorders in a suburban US community. Acta Psychiatrica Scandinavica 57, 219-231.

Wells, J. E., Robins, L. N., Bushnell, J. A., Jarosz, M. A. \& OakleyBrowne, M. A. (1994). Perceived barriers to care in St. Louis (USA) and Christchurch (NZ): reasons for not seeking professional help for psychological distress. Social Psychiatry and Psychiatric Epidemiology 29, 155-164.

Wing, J. K., Mann, S. A., Leff, J. P. \& Nixon, J. N. (1978). The concept of a case in psychiatric population surveys. Psychological Medicine 8, 203-219. 